\title{
PERENCANAAN PEMELIHARAAN MOTOR DIESEL DENGAN METODE RCM (RELIABILITY CENTERED MAINTENANCE) PADA PLTG TELUK LEMBU PEKANBARU
}

\author{
Darno \\ Program Studi Teknik Industri, Fakultas Teknik, Universitas Muhammadiyah Riau \\ Jalan Tuanku Tambusai Ujung, Kecamatan Tampan, Kelurahan Delima, Kota Pekanbaru, Riau 28291 \\ Email : 160103047@student.umri.ac.id
}

\begin{abstract}
Teluk Lembu Gas Power Plant (PLTG) is one type of power plant that uses the power of burning fuel and high pressure air. To be able to meet the needs of electrical energy on the island of Sumatra, especially in the Riau region,electricity production must not experience a decrease in productivity due to equipment damage. Obstacles that arise are frequent downtime unexpectedresulting in the production of electricity is interrupted or even to cause derating caused by damage to the operational when the engine is running. This study aims to provide recommendations for equipment maintenance andtime intervals optimal inspectionin the generator system. The research method used is Reliability Centered Maintenance (RCM) withanalysis quantitative. Where are the stages of implementing the RCM method, namely determining thecomponents criticalin the PLTG generator engine, determining thevalues, determining the Mean Time to Failure (MTTF) and Mean Time to Repair (MTTR)time interval optimal maintenance, and making a table of causes of damage to thecomponents generator engine. After analyzing it, it was found that thecomponent criticalof PLTG Teluk Lembu is the Diesel Motor. This is obtained based on the component with the highest frequency of damage, namely 13 damage during a period of 1 year. From the results of data processing, it is obtained that the MTTF value is 0.92441 hours and the MTTR value is 0.89014 hours. Theinspection time interval optimalis 25 days, so it is advisable to carry out Corrective and Preventive maintenance activities for Diesel Motorcycles periodically every 25 days (PM 25D) in order to increase the reliability of the Diesel Motor.
\end{abstract}

Keywords: Maintenance, RCM (Reliability Centered Maintenance), Critical Components

\begin{abstract}
ABSTRAK
Pembangkit Listrik Tenaga Gas (PLTG) Teluk Lembu merupakan salah satu jenis pembangkit listrik yang menggunakan tenaga hasil pembakaran bahan bakar dan udara yang bertekanan tinggi. Untuk dapat memenuhi kebutuhan energi listrik di pulau Sumatera khususnya wilayah Riau, produksi listrik tidak boleh mengalami penurunan produktifitas yang dikarenakan oleh kerusakan peralatan. Kendala yang muncul yaitu seringnya terjadi downtime secara tidak terduga yang mengakibatkan produksi listrik terganggu atau bahkan sampai menimbulkan derating yang disebabkan oleh kerusakan pada saat operasional mesin berjalan. Penelitian ini bertujuan untuk memberikan usulan pemeliharaan peralatan dan interval waktu pemeriksaan yang optimal pada system pengbangkit. Metode penelitian yang digunakan adalah Reliability Centered Maintenance (RCM) dengan analisa kuantitatif. Dimana tahapan implementasi metode RCM yaitu menentukan komponen kritis pada mesin pembangkit PLTG, menentukan nilai Mean Time to Failure (MTTF) dan Mean Time to Repair (MTTR), menentukan interval waktu pemeliharaan yang optimal, dan membuat tabel penyebab kerusakan pada komponen mesin pembangkit. Setelah dilakukan analisa, maka didapatkan bahwa komponen kritis PLTG Teluk Lembu adalah Motor Diesel. Hal ini didapat berdasarkan pada komponen dengan frekuensi kerusakan terbanyak yakni sebanyak 13 kerusakan selama periode 1 tahun. Dari hasil pengolahan data didapatkan nilai MTTF sebesar 0,92441 jam dan nilai MTTR sebesar 0,89014 jam
\end{abstract}


interval waktu pemeriksaan yang optimal adalah 25 hari, sehingga disarankan melakukan kegiatan Corrective dan Preventive maintenance Motor Diesel secara periodik setiap 25 hari (PM 25D) agar dapat meningkatkan keandalan Motor Diesel tersebut.

Kata Kunci : Perawatan, RCM (Reliability Centered Maintenance), Komponen Kritis

\section{Pendahuluan}

Dalam upaya meninggkatkan kebutuhan energi listrik di Indonesia, peningkatan penduduk indonesia setiap tahunnya mengalami peningkatan seiring dengan tingkat pertumbuhan ekonomi yang sangat senifikan. Pertumbuhan penduduk secara nasional sebersar $1,3 \%$ pertahun dengan asumsi perkembangan/pertumbuhan ekonomi nasional rata-rata sebesar $6,1 \%$ per tahun.

Jenis pembangkit PLTG ini salah satu jenis pembangkit yang menggunakan tenaga hasil pembakaran bahan bakar dan udara yang bertekanan tinggi. Untuk menghasilkan listrik, tenaga dari hasil pembakaran dan udara bertekanan tinggi akan memutar turbin gas melalui sudu-sudu menjadi gerak putar pada poros turbin dan akan diteruskan pada generator. Pada komponen generator inilah gerak putar akan tegak lurus dengan medan magnet sehingga menghasilkan gaya gerak listrik.

Di PLTG sendiri telah mempunyai jadwal berkaitan dengan pemeliharaan terhadap kedua mesin, akan tetapi masih terjadi mesin rusak sebelum adanya pemeliharaan yang dijadwalkan oleh pihak perusahaan. Akibatnya terjadi corrective maintenance yang akan menimbulkan kerugian yang tidak sedikit. Hal ini berkaitan dengan tingkat keandalan mesin yang rendah. Konsekuensi terhadap operasional produksi terjadi disemua jenis kegagalan yaitu timbulnya downtime yang menimbulkan biaya dan kemungkinan juga kerusakan pada komponen-komponen yang lain.

Untuk melakukan perbaikan pada kerusakan mesin/peralatan secara tiba-tiba merupakan permasalahan besar yang sering ditemui di PLTG Teluk Lembu yang mengakibatkan seringnya terjadi penghentian operasi, dan mengakibatkan proses produksi harus terhenti untuuk sementara waktu. Terjadinya kerusakan pada mesin memang tidak dapat diketahui secara pasti kapan mesin akan terhenti. karena itu diperlukan suatu tindakan perawatan mesin/peralatan untuk dapat mencegah terjadinya kerusakan pada mesin pembangkit.

PLTG melakukan perawatan (maintenance) terhadap kedua mesin pembangkit listrik tersebut agar kegiatan operasional dapat terlaksana dengan baik. Berikut ini merupakan data historis 
kerusakan yang berakibatkan downtime pada komponen mesin PLTG Teluk Lembu.

Tabel 1 Data Downtime Pada Komponen Pembangkit PLTG Teluk Lembu Maret 2019 Februari 2020

\begin{tabular}{|c|l|c|}
\hline No & Komponen & $\begin{array}{c}\text { Downtime } \\
\text { (Menit) }\end{array}$ \\
\hline 1 & Motor Diesel & 4140 \\
\hline 2 & Load Gear & 840 \\
\hline 3 & Turbin & 540 \\
\hline 4 & Fuel Gas & 480 \\
\hline 5 & IGV & 420 \\
\hline 6 & Trafo & 420 \\
\hline 7 & Filter & 360 \\
\hline 8 & Racet & 300 \\
\hline 9 & Radiator & 240 \\
\hline 10 & PS & 120 \\
\hline
\end{tabular}

Sumber : PLTG Teluk Lembu 2020

Berdasarkan data kerusakan mesin tersebut, maka diperlukan evaluasi terhadap perencanaan maintenance mesin pembangkit listrik agar sesuai dan tidak menimbulkan kegagalan pada sistem pembangkit.

\section{Metodologi}

Untuk melaksanakan riset diperlukan tahapan yang dimana suatu rangkaian proses yang berkaitan secara tepat dan sistematis. Berikut tahapan-tahapan yang dilakukan dalam penelitian:

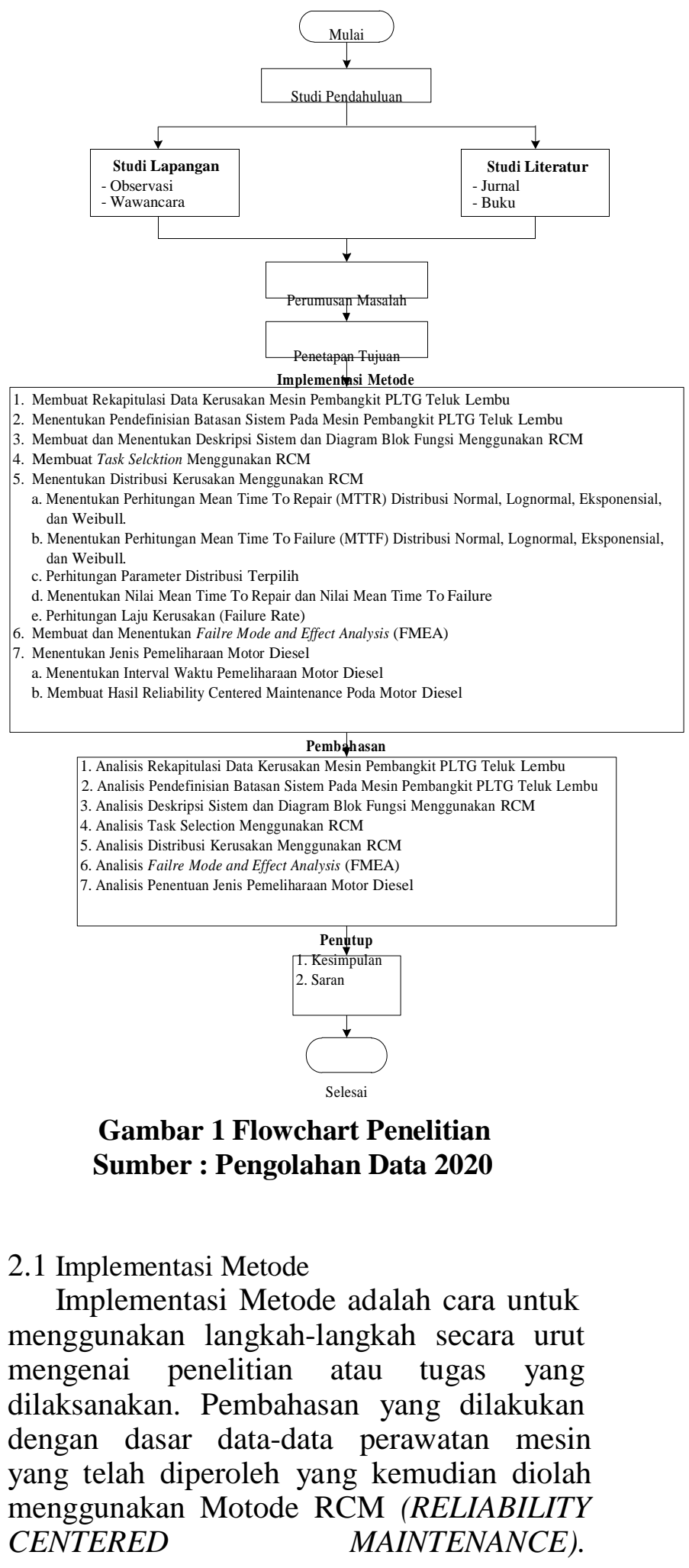




\subsection{Tahapan Penerapan Reliabity Centered Maintenance}

Dalam menentukan reliability centered maintenace, terlebih menentukan tahapantahapan yang dibutuhkan dalam RCM.

1. Memilih pengumpulan informasi

2. Pendefinisian batasan system

3. Deskripsi sistem dan Diagram Blok Fungsi (Function Block Diagram)

4. Taks Selection

5. Distribusi Kerusakan

6. Failure Mode and Effect Analysis (FMEA)

7. Pemilihan tindakan

2.3 Pemilihan Sistem dan Pengumpulan

Informasi

Keputusan yang diterapkan dalam memilih metode RCM, terdapat 2 bahan yang dijadikan pemikiran:

a. Sistem yang akan dilakukan analisis, fungsi dan kegagalan fungsi komponen merupakan proses analisa reliability centered maintenance pada tingkat sistem akan memberikan informasi yang lebih jelas.

b. Dalam melakukan pemilihan sistem seluruh sistem akan dilakukan proses analisa.

3. Hasil Dan Pembahasan

a. Membuat Rekapitulasi Data Kerusakan Mesin Pembangkit PLTG Teluk Lembu.

Tabel 2 Merekapitulasi Kerusakan Komponen Mesin Pembangkit PLTG Teluk Lembu

\begin{tabular}{|c|c|c|c|c|c|}
\hline $\mathrm{N}_{0}$ & Waktu Terjadi & $\begin{array}{c}\text { Downtime } \\
\text { (Menit) }\end{array}$ & Deskripsi Kerusakan & Lokasi & Komponen \\
\hline 1 & 1-Mar-2019 & 120 & Baut Koping Load Gear Kendor & $\mathrm{G} 3$ & Load Gear \\
\hline 2 & 4-Mar-2019 & 420 & $\begin{array}{l}\text { Kebocoran Oli Diarea Load Gear, ACC Gear dan } \\
\text { Starting Diesel }\end{array}$ & G3 & Load Gear \\
\hline 3 & 5-Mar-2019 & 300 & Pompa Racet Rusak & $\mathrm{G3}$ & Racet \\
\hline 4 & 8-Mar-2019 & 1440 & Motor Diesel Terbakar & G3 & Motor \\
\hline 5 & 11-Mar-2019 & 240 & Housing Motor 88 BA Rusak & $\mathrm{G} 3$ & Diesel \\
\hline 6 & 12-Mar-2019 & 180 & Injektor Macet & $\mathrm{G3}$ & Diesel \\
\hline 7 & 14-Mar-2019 & 180 & Pressure Switch Tidak Bekerja & G3 & Diesel \\
\hline 8 & 14-Mar-2019 & 240 & Pressure Oli Starting Diesel Tidak Normal & $\mathrm{G3}$ & Diesel \\
\hline 9 & 15-Mar-2019 & 180 & Pipa Hisap Pompa 0li Patah & $\mathrm{G} 3$ & Diesel \\
\hline 10 & 16-Mar-2019 & 120 & Terjadi Alarm Failure To Fire & $\mathrm{G3}$ & Diesel \\
\hline 11 & 16-Mar-2019 & 180 & Selenoid 20 VG2 Tidak Bekerja & $\mathrm{G3}$ & Diesel \\
\hline 12 & 19-Mar-2019 & 180 & Pressure Lube 0il Tidak Bekerja Normal & $\mathrm{G3}$ & Turbin \\
\hline 13 & 20-Mar-2019 & 180 & Pompa Lube Oil Rusak & $\mathrm{G} 3$ & Diesel \\
\hline 14 & 20-Mar-2019 & 540 & Manhole Load Gear Rusak & $\mathrm{G} 3$ & Diesel \\
\hline 15 & 21-Mar-2019 & 180 & Pressure 63 DM Tidak Bekerja & G3 & Diesel \\
\hline 16 & 22-Mar-2019 & 120 & IGV Tidak Bekerja & G3 & IGV \\
\hline 17 & 26-Mar-2019 & 120 & Fuel Oil Pump Rusak & $\mathrm{G} 3$ & Motor \\
\hline 18 & 27-Mar-2019 & 120 & Gangguan Pada Sistem Fuel Gas & $\mathrm{G} 2$ & Fuel Gas Sistem \\
\hline 19 & 27-Mar-2019 & 180 & Filter Gas Rusak & $\mathrm{G} 2$ & Fuel Gas Sistem \\
\hline 20 & 28-Mar-2019 & 180 & Filter Scrubber A Dan B Rusak & $\mathrm{G} 2$ & Nozzle \\
\hline 21 & 3-Apr-2019 & 120 & Kabel PS Rusak & $\mathrm{G} 2$ & PS \\
\hline 22 & 24-Apr-2019 & 120 & Filter Udara Rusak & $\mathrm{G} 2$ & Filter \\
\hline 23 & 12-Jun-2019 & 360 & Kebocoran Oli Diarea Load Gear & $\mathrm{G} 2$ & Turbin \\
\hline 24 & 3-Sep-2019 & 420 & $\begin{array}{l}\text { Infeksi Pipa Dehidran Breather dan Tanki } \\
\text { Konservator Oli Trafo }\end{array}$ & $\mathrm{G} 3$ & Trafo \\
\hline 25 & 4-Sep-2019 & 180 & Kabel Selenoit 20TV Mengalami Short Circuit & $\mathrm{G} 2$ & IGV \\
\hline 26 & 4-Sep-2019 & 120 & Kontaktor 161K2 Rusak & $\mathrm{G} 2$ & IGV \\
\hline 27 & 24-Sep-2019 & 360 & Hydraulic Ratchet Starting Clutch Patah & $\mathrm{G3}$ & Motor \\
\hline 28 & 9-Dec-2019 & 120 & Filter Air Intek Rusak & $\mathrm{G} 2$ & Filter \\
\hline 29 & 11-Dec-2019 & 120 & Filter Air Intek Rusak & $\mathrm{G3}$ & Filter \\
\hline 30 & 12-Dec-2019 & 120 & Elektromotor Radiator Bantu Rusak & $\mathrm{G} 2$ & Radiator \\
\hline 31 & 17-Dec-2019 & 120 & Bearing Elektromotor Radiator Rusak & $\mathrm{G}^{2}$ & Radiator \\
\hline 32 & 6-Jan-2020 & 300 & Kebocoran limit switch pada sistem panel gas & $\mathrm{G} 2$ & Load Gear \\
\hline
\end{tabular}

\section{Sumber : PLTG Teluk Lembu 2020}

b. Membuat Dan Menentukan Deskripsi Sistem Dan Diagram Blok Fungsi (Function Block Diagram). Pada tahap ini dilakukan pendeskripsian sistem untuk mengidentifikasi sistem yang terdapat pada komponen kritis mesin pembangkit PLTG. Penentuan komponen kritis pada mesin pembangkit berdasarkan jumlah downtime kerusakan komponen tertinggi. 
Tabel 3 Nilai Downtime Pada Komponen Mesin Pembangkit PLTG Teluk Lembu

\begin{tabular}{|l|c|c|c|c|}
\hline Komponen & Fre kue nsi & $\begin{array}{c}\text { Downtime } \\
(\text { Me nit })\end{array}$ & $\begin{array}{c}\text { Downtime } \\
(\mathbf{\%})\end{array}$ & $\begin{array}{c}\text { Kumulatif } \\
\text { Downtime (\%) }\end{array}$ \\
\hline Motor Diesel & 13 & 4140 & 52.67 & 52.67 \\
\hline Load Gear & 3 & 840 & 10.68 & 63.35 \\
\hline Turbin & 2 & 540 & 6.87 & 70.22 \\
\hline Fuel Gas Sistem & 3 & 480 & 6.11 & 76.33 \\
\hline IGV & 3 & 420 & 5.34 & 81.67 \\
\hline Trafo & 1 & 420 & 5.34 & 87.01 \\
\hline Filter & 3 & 360 & 4.58 & 91.59 \\
\hline Racet & 1 & 300 & 3.82 & 95.41 \\
\hline Radiator & 2 & 240 & 3.07 & 98.48 \\
\hline PS & 1 & 120 & 1.52 & 100 \\
\hline JUMLAH & 32 & 7860 & 100 & \\
\hline
\end{tabular}

Sumber : Pengolahan Data Komponen Mesin Pembangkit 2020

Dari data di atas, maka didapatkan komponen dengan nilai downtime kerusakan tertinggi yaitu komponen motor diesel sebanyak 13 kali dengan total waktu downtime 4140 menit.

c. Membuat Taks Selection Dengan Menggunakan RCM

Pada tahap task selection dimana mode kegagalan telah diketahui, selanjutnya menentukan kebijakan dari kategori perawatan. Time to Repair dan Time To Failure adalah waktu yang digunakan untuk mencari data waktu kerusakan, waktu lama perbaikan sampai selesai perbaikan diambil dari waktu kerusakan. Sedangkan waktu kerusakan awal yang telah diperbaiki hingga terjadi kerusakan berikutnya waktu yang diambil dari data time to failure. Data diambil dari selisih waktu kerusakan dikurangi dengan waktu perbaikan, maka didapatkan hasil sebagai berikut.

Tabel 4 Data Time To Repair (TTR) Dan Time To Failure (TTF) Motor Diesel

\begin{tabular}{|c|c|c|c|c|}
\hline No & $\begin{array}{c}\text { Waktu } \\
\text { Te rjadi }\end{array}$ & $\begin{array}{c}\text { Downtime } \\
\text { (Me nit) }\end{array}$ & $\begin{array}{c}\text { TTR } \\
(\text { Jam) }\end{array}$ & $\begin{array}{c}\text { TTF } \\
\text { (Jam) }\end{array}$ \\
\cline { 5 - 5 } & 8-Mar-2019 & 1440 & 24 & 0 \\
\hline 2 & 11-Mar-2019 & 240 & 4 & 72 \\
\hline 3 & 12-Mar-2019 & 180 & 3 & 24 \\
\hline 4 & 14-Mar-2019 & 180 & 3 & 48 \\
\hline 5 & 14-Mar-2019 & 240 & 4 & 48 \\
\hline 6 & 15-Mar-2019 & 180 & 3 & 24 \\
\hline 7 & 16-Mar-2019 & 120 & 2 & 24 \\
\hline 8 & 16-Mar-2019 & 180 & 3 & 24 \\
\hline 9 & 20-Mar-2019 & 180 & 3 & 96 \\
\hline 10 & 20-Mar-2019 & 540 & 9 & 96 \\
\hline 11 & 21-Mar-2019 & 180 & 3 & 24 \\
\hline 12 & 26-Mar-2019 & 120 & 2 & 120 \\
\hline 13 & 24-Sep-2019 & 360 & 6 & 4368 \\
\hline
\end{tabular}

Sumber : Pengolahan Data Time To Repair (TTR) Dan Time To Failure (TTF) Motor Diesel 2020

d. Menentukan distribusi kerusakan dengan menggunakan RCM

Untuk menghitung nilai Mean Time To Repair (MTTR) dan nilai Mean Time To Failure (MTTF) terlebih dahulu menghitung nilai index of fit (r). Terdapat 4 distribusi yang dipakai dalam menentukan index of fit (r), yaitu distribusi normal, lognormal, eksponensial, dan weibull. Berikut adalah perhitungan index of fit (r) dari beberapa distribusi, yang dimana data perhitungan antar distribusi terlampir pada Lampiran 1 - Lampiran 8.

e. Perhitungan Laju Kerusakan
(Failure Rate)
Untuk menghitung laju kerusakan/failure rate terlebih dahulu menghitung nilai probability density function, cummulative distribution function, dan reliability function menggunakan Microsoft Excel. Rumus yang digunakan adalah sebagai berikut, yang dimana data perhitungan untuk menghitung fungsi kepadatan probabilitas dan fungsi distribusi kumulatif terlampir pada Lampiran 9 Lampiran 11.

1. Fungsi Kepadatan Probabilitas / Probability Density Function [ $\mathrm{f}(\mathrm{t})]$ 
$=$ LOGNORMAL.DIST $\left(\mathrm{t} \_\right.$med,t_i, n, $\mu, \mathrm{s})$

Keterangan:

t_med : Nilai tengah waktu kerusakan $=11,37318$

t_i : Data waktu kerusakan ke-i

$\mathrm{n}:$ Banyaknya data kerusakan $=12$

$\mu:$ Nilai tengah $=4,18396$

$\mathrm{s}:$ Standar deviasi $=0,07731$

2. Fungsi Distribusi Kumulatif/

Cummulative Distribution Function $[\mathrm{F}(\mathrm{t})]=$ LOGNORMAL.DIST (t_med,t_i, n, $\mu, s)$

Keterangan:

t_med : Nilai tengah waktu kerusakan $=11,37318$

t_i : Data waktu kerusakan ke-i

$\mathrm{n}:$ Banyaknya data kerusakan $=12$

$\mu:$ Nilai tengah $=4,18396$

$\mathrm{s}:$ Standar deviasi $=0,07731$

3. Fungsi Keandalan/Reliability Function $[R(t)]$

$\mathrm{R}(\mathrm{t})=1-\mathrm{F}(\mathrm{t})$

4. Laju Kerusakan/Failure Rate $(\lambda)$

$\lambda=\mathrm{f}(\mathrm{t})-\mathrm{R}(\mathrm{t})$

Dengan menggunakan persamaan diatas pada Microsoft Excel, maka didapatkan hasil seperti tabel di bawah ini.

Tabel 5 Nilai Laju Kerusakan (Failure Rate) Motor Diesel

\begin{tabular}{|c|c|c|c|c|}
\hline$i$ & $f(t)$ & $F(t)$ & $R(t)$ & $\begin{array}{l}\text { Failure } \\
\text { Rate }\end{array}$ \\
\hline 1 & 0 & -54.11926 & 55.11926 & -55.11926 \\
\hline 2 & 0.00201 & -45.15341 & 46.153408 & -46.1514 \\
\hline 3 & 0.00506 & -39.90881 & 40.908809 & -40.90375 \\
\hline 4 & 0.00805 & -36.18769 & 37.187686 & -37.17964 \\
\hline 5 & 0.01085 & -33.30125 & 34.301255 & -34.2904 \\
\hline 6 & 0.01345 & -30.94296 & 31.942957 & -31.92951 \\
\hline 7 & 0.01586 & -28.94904 & 29.949036 & -29.93318 \\
\hline 8 & 0.01811 & -27.22183 & 28.221834 & -28.20372 \\
\hline 9 & 0.02022 & -25.69836 & 26.698357 & -26.67814 \\
\hline 10 & 0.02221 & -24.3354 & 25.335403 & -25.31319 \\
\hline 11 & 0.02409 & -23.1027 & 24.102703 & -24.07861 \\
\hline 12 & 0.02587 & -21.97711 & 22.977105 & -22.95124 \\
\hline
\end{tabular}

\section{Failure Rate}

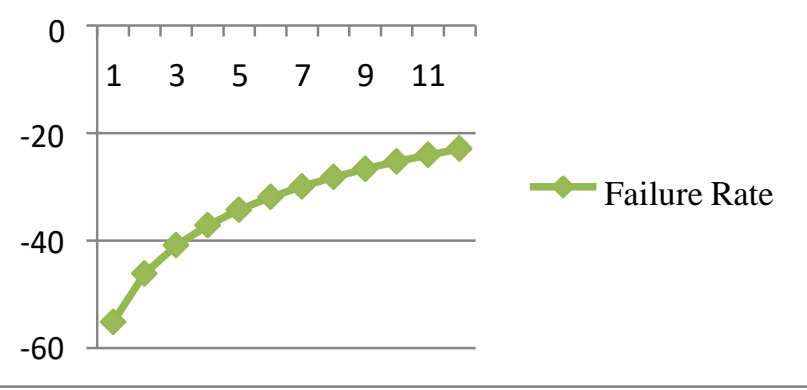

\section{Gambar 1 Grafik Laju Kerusakan Motor Diesel}

f. Membuat Dan Menentukan Failure Mode and Effect Analysis (FMEA) Suatu keadaan yang dapat menyebabkan kegagalan fungsional yaitu mode kegagalan. Mode ini mencakup semua kegagalan yang terjadi sehingga menggambarkan dampak kegagalan kemudian bisa digunakan untuk menentukan konsekuensi dan penyebab pengantisipasi mencegah, mendeteksi, dan memperbaiki. Ada 3 penyebab kegagalan (failure mode) yaitu.

Tabel 6 FMEA Setelah Dilakukan Metode RCM

\begin{tabular}{|c|c|c|c|c|c|}
\hline $\mathbf{N}$ & $\begin{array}{c}\text { Equi } \\
\text { pme } \\
\text { nt }\end{array}$ & $\begin{array}{c}\text { Fail } \\
\text { ure } \\
\text { Mod } \\
\text { e }\end{array}$ & $\begin{array}{c}\text { Failu } \\
\text { re } \\
\text { Effec } \\
\text { t }\end{array}$ & $\begin{array}{c}\text { Penyebab } \\
\text { Kerusaka } \\
\text { n }\end{array}$ & $\begin{array}{c}\text { Usulan } \\
\text { Pemelihar } \\
\text { aan }\end{array}$ \\
\hline 1 & $\begin{array}{l}\text { Mot } \\
\text { or } \\
\text { Dies } \\
\text { el }\end{array}$ & $\begin{array}{l}\text { Rusa } \\
\text { k }\end{array}$ & $\begin{array}{l}\text { Teka } \\
\text { nan } \\
\text { terlal } \\
\text { u } \\
\text { tinggi }\end{array}$ & $\begin{array}{l}\text { Pressure } \\
\text { oil starting } \\
\text { diesel } \\
\text { tidak } \\
\text { normal, } \\
\text { injector } \\
\text { macet, } \\
\text { motor } \\
\text { diesel } \\
\text { terbakar, } \\
\text { hausing } \\
\text { motor } 88 \\
\end{array}$ & $\begin{array}{l}\text { Dilakukan } \\
\text { inspeksi } \\
\text { dan } \\
\text { preventive } \\
\text { maintenanc } \\
e \text { secara } \\
\text { periodik } \\
\text { setiap } 26 \\
\text { hari }\end{array}$ \\
\hline
\end{tabular}




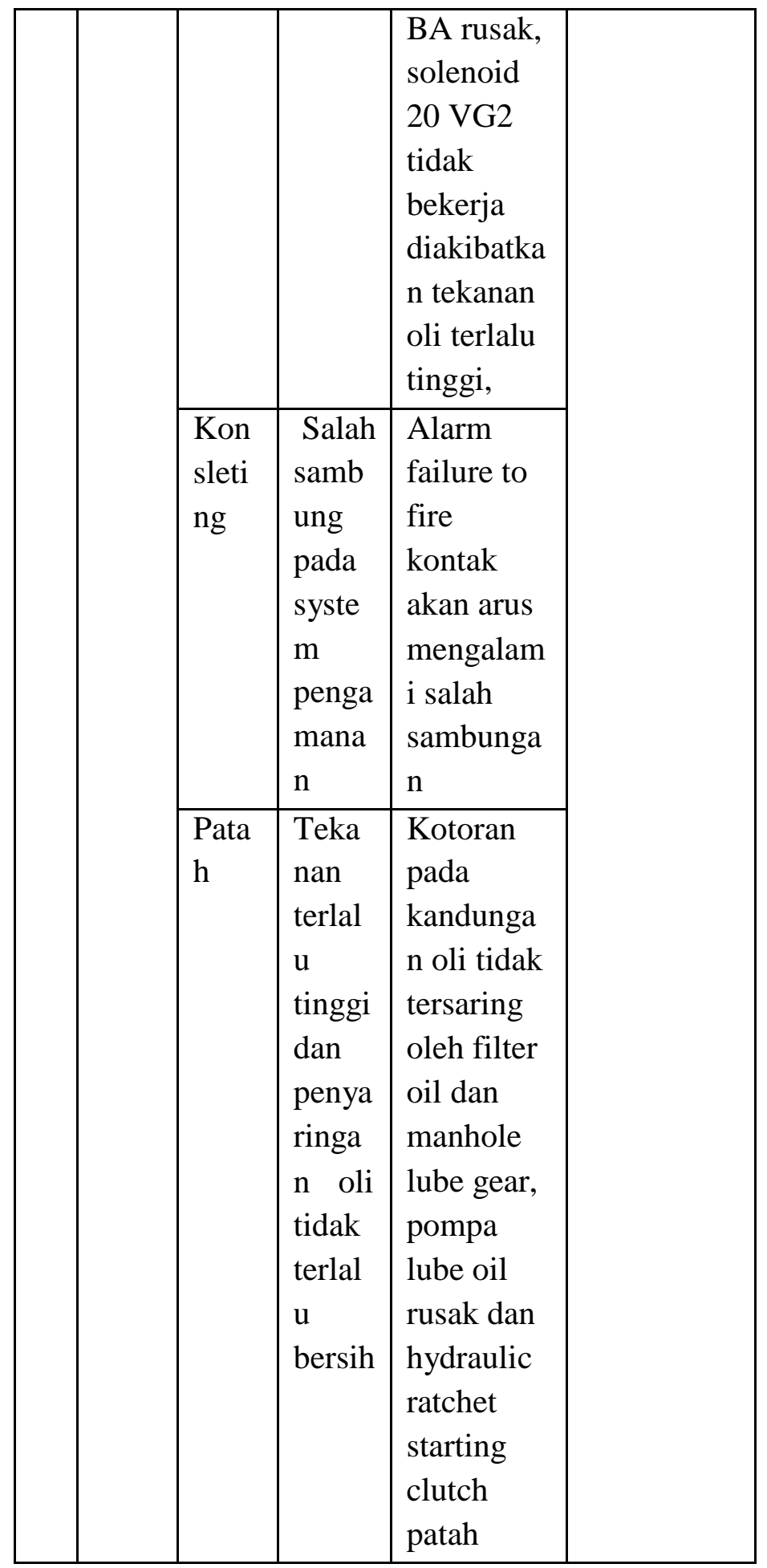

\section{Kesimpulan}

1. Dari rekapitulasi data kerusakan mesin pembangkit terdapat 32 kali downtime selama periode 1 tahun dari bulan maret 2019 - februari 2020. Hasil pendefinisian sistem terdapat 10 komponen kritis (downtime) yaitu komponen Motor Diesel, Load Gear, Turbin, Fuel Gas Sistem, IGV, Trafo, Filter, Racet, Radiator, dan PS. Penentuan deskripsi sistem pada mesin pembangkit dilihat dari jumlah downtime kerusakan komponen yaitu komponen motor diesel dengan jumlah sebanyak 13 kerusakan dan total waktu downtime sebanyak 4140 menit. Hasil task selection diambil dari menentukan kebijakan kategori perawatan dimana jumlah downtime sebanyak 4140 menit, jumlah TTR sebanyak 69 jam, dan jumlah TTF sebanyak 4368 jam.

2. Hasil penentuan distribusi kerusakan, terdapat 4 distribusi yaitu distribusi normal, lognormal, eksponensial dan weibull untuk setiap perhitungan Mean Time to Repair (MTTR) dan Mean Time to Failure (MTTF). Dari keempat distribusi tersebut didapat distribusi Lognormal dengan frekuensi tertinggi yaitu 0,89014 dengan jumlah index of fit (r) 0,88127 untuk perhitungan MTTR dan 0,92441 dengan jumlah index of fit (r) 0,78929 untuk perhitungan MTTF.

3. Dari hasil analisis ada 3 failure mode penyebab terjadinya downtime untuk komponen motor diesel yaitu terjadinya komponen rusak dikarenakan tekanan terlalu tinggi, konsleting dikarenakan salah sambungan pada sistem pengamanan, dan komponen patah dikarenakan tekanan terlalu tinggi dan penyaringan oli tidak terlalu bersih.

4. Nilai s (Standar deviasi) yang didapat adalah 0,07731. Berdasarkan 
nilai tersebut maka jenis pemeliharaan motor diesel yang sesuai adalah Corrective dan Preventive Maintenance.

\section{Daftar Pustaka}

[1] Ahmadi Noor dan Nur Yulianti Hidayah. 2017. Analisis Pemeliharaan Mesin Blowmould Dengan Metode RCM Di PT. CCAI

[2] Ahyari. 2002. Manejemen produksi pengendalian produksi. Yogyakarta : BPFE.

[3] Ansori N. dan I. Mustajib, 2013. Sistem perawatan Terpadu. Yogyakarta: Graha Ilmu.

[4] Arsyadiaga, dan Duhan, 2017, Analisis Penentuan Waktu Pemeliharaan Mesin Dengan Metode RCM (Reliability Centered Maintenance) Di PT Sanmas Dwika Abadi, Jakarta.

[5] Assauri. 2008. Manejemen produksi dan operasi. Jakarta : Universitas Indonesia

[6] Asisco Hendro, Kifayah Amar dan Yandra Rahadian Perdana. 2012. Usulan Perencanaan Perawatan Mesin Dengan Metode Reliability Centered Maintenance (Rcm) Di Pt. Perkebunan Nusantara VII (Persero) Unit Usaha Sungai Niru Kab.Muara Enim.

[7] D.H. Stamatis. 1995. Failure Mode and Effect Analysis: FMEA from Theory to Execution. Milwaukee: ASQC Quality Press.

[8] Ebeling, 1997. jenis dan kegiatan perawatan maintenance terpadu Indonesia: Kajian pustaka.

[9] Gaspersz. 2002. penilaian skala severity atau tingkat keparahan : Dasar ilmu penelitian.

[10] Haizer, dan Render. 2011. Manajemen operrasi buku kedua. Jakarta : salemba empat.

[11] Harsanto. 2013. Dasar ilmu manajemen operasi. Bandung : UNPAD.
[12] J August. 1999. Applied ReliabilityCentered Maintenance, Oklahoma: Penn Well.

[13] Kurniawati Agustina Dwi dan Muhammad Lutfan Muzaki. 2017. Analisis Perawatan Mesin dengan Pendekatan RCM dan MVSM.

[14] Kurniawan dan Fajar. 2013. Manajemen Perawatan Industri: Teknik dan Aplikasi Implementasi Total Productive Maintenance (TPM), Preventive Maintenance dan Reability Centered Maintenance (RCM). Yogyakarta: Graha Ilmu.

[15] Lukodono R, Pratikno, dan R. Soenoko. Analisis Penerapan Metode RCM dan MVSM untuk Meningkatkan Keandalan Pada Sistem Maintenance (Studi Kasus PG. X). Jurnal Rekayasa Mesin, Volume IV

[16] Manzini. 2010. Maintenance for industrial systems. London : Springer

[17] Montgomery. 2005. Wind energy analysis of grenada, an estimation using weibull desenty function. Renew. Energy 28.

[18] Moubray dan John, 1997, Reliability-centred Maintenance II, Second Edition, ButterworthHeinemann, Oxford.

[19] Otaya dan Lian G. 2016, Distribusi Probabilitas Weibull Dan Aplikasinya (Pada Persoalan Keandalan (Reliability) Dan Analisis Rawatan (Mantainability), Vol. 4, Institut Agama Islam Negeri Sultan Amai, Gorontalo.

[20] Pramesti, Vanni D. dan Susetyo. Ag E., 2018. Analisis Penerapan Metode Reliability Centered Maintenance (RCM) Untuk Meningkatkan Keandalan Pada Sistem Maintenance, Yogyakarta : Universitas Sarjanawiyata Tamansiswa. 
[21] Prawirosentono. 2001. Menejemen opersi. Jakarta : Bumi Aksara.

[22] Rachman Hamim, Annisa Kesy Garside dan Heri Mujayin Kholik. 2017. Usulan Perawatan Sistem Boiler dengan Metode Reliability Centered Maintenance (RCM).

[23] Sari Puspita Diana dan Mukhammad Faizal Ridho. 2016, Evaluasi Manajemen Perawatan Dengan Metode Reliability Centered Maintenance (RCM) II Pada Mesin Blowing I di Plant I PT. Pisma Putra Textile.

[24] Sehrawat dan Narang. 2001. Production management. Pengertian pemeliharaan. Nai sarak :Dhapahat Rai Co

[25] Smith Anthony. 1999. Ilmu peluang statistika untuk insinyur dan ilmuan, Edisi ke-4, Bandung : ITB

[26] Smith and Hinchcliffe. 2004. Management Operation, jenis-jenis kerusakan : Logic Tree Analysis (LTA).

[27] Susanto Dwi Agustinus dan Hery Hamdi Azwir 2017, Perencanaan Perawatan Pada Unit Kompresor Tipe Screw Dengan Metode RCM di Industri Otomotif.

[28] Tampubolon. 2004. Manajemen operasional. Jakarta : Ghalia Indonesia.

[29] Walpole. 1995. Pengantar statistika edisis 3. Jakarta : PT Gramedia Pustaka Utama. 